\title{
Caracterização química, atividade antioxidante e formulação de doces com feijão azuki (Vigna angularis)
}

\author{
Chemical composition, antioxidant activity and development of desserts with azuki \\ beans (Vigna angularis)
}

\author{
Daniela Castilho Orsi ${ }^{1 *}$, Adriana Cândida Faustino $\mathrm{Nishi}^{2}$, Vania Silva Carvalho², Eduardo Ramirez Asquieri \\ 1 Universidade de Brasília (UnB), Faculdade de Farmácia (FCE), Brasília/DF - Brasil \\ 2 Universidade Federal de Goiás (UFG), Faculdade de Farmácia, Goiânia/GO - Brasil
}

\section{${ }^{*}$ Corresponding Author}

Daniela Castilho Orsi, Universidade de Brasília (UnB), Faculdade de Farmácia (FCE), Centro Metropolitano, Conjunto A, Lote 01, Ceilândia, CEP: 72220-900, Brasilia/DF - Brasil, e-mail: danielacastilhoorsi@gmail.com

Cite as: Chemical composition, antioxidant activity and development of desserts with azuki beans (Vigna angularis). Braz. J. Food Technol., v. 20, e2016174, 2017

Received: Dec. 09, 2016; Accepted: June 30, 2017

\section{Resumo}

No Japão, o feijão azuki é comumente usado na elaboração de doce, observando-se que a sua casca vermelha é rica em antioxidantes. No Brasil, o feijão azuki ainda é pouco consumido e o doce de feijão é pouco conhecido pelos brasileiros. O objetivo deste estudo foi caracterizar quimicamente o feijão azuki vermelho (Vigna angularis), bem como avaliar a influência do cozimento sobre o seu teor de compostos fenólicos e a sua atividade antioxidante. Buscou-se também avaliar a composição química dos doces formulados com feijão azuki. Os resultados obtidos para a composição química mostraram que o feijão azuki apresentou elevados teores de carboidratos $(65,60 \mathrm{~g} / 100 \mathrm{~g})$ e proteínas $(17,87 \mathrm{~g} / 100 \mathrm{~g})$. O feijão azuki cozido, comparado ao feijão azuki cru, perdeu grande parte dos compostos fenólicos, mas ainda manteve quase metade da atividade antioxidante. Os doces de feijão azuki em massa e em pasta apresentaram, respectivamente, alto teor de carboidratos de 67,09 e 46,20 g/100 g, teores de proteínas de 4,02 e 6,48 g/100 g, e baixo teor de lipídios de 0,33 e 2,73 g/100 g. O feijão azuki vermelho mostrou ter um bom potencial tecnológico para sua utilização no processamento dos doces de feijão.

Palavras-chave: Feijão azuki; Composição química; Atividade antioxidante; Doce de feijão.

\section{Abstract}

In Japan, azuki beans are commonly used in the preparation of desserts and their red seed coats are rich in antioxidants. In Brazil, azuki beans are still little consumed and the bean dessert little known by Brazilians. The aim of this study was to characterize red azuki beans (Vigna angularis) by means of chemical analyses, evaluate the influence of cooking on the total phenolic compound contents and antioxidant activity, and also evaluate the chemical composition of desserts formulated with azuki beans. The results obtained for the chemical composition showed that azuki beans presented high carbohydrate $(65.60 \mathrm{~g} / 100 \mathrm{~g})$ and protein $(17.87 \mathrm{~g} / 100 \mathrm{~g})$ contents. When compared to raw azuki beans, the cooked beans had lost most of the phenolic compounds, but still maintained nearly half of the antioxidant activity. The azuki bean desserts in the solid and paste forms presented, respectively, high carbohydrate contents (67.09 and $46.20 \mathrm{~g} / 100 \mathrm{~g}$ ), good protein contents $(4.02$ and $6.48 \mathrm{~g} / 100 \mathrm{~g})$ and low lipid contents $(0.33$ and $2.73 \mathrm{~g} / 100 \mathrm{~g})$. The red azuki beans showed good technological potential for use in the processing of bean desserts.

Keywords: Azuki beans; Chemical composition; Antioxidant activity; Bean desserts. 


\section{Introdução}

O feijão azuki (Vigna angularis) é uma espécie originária das regiões tropicais da Ásia e representa um alimento de amplo consumo na dieta de países como o Japão, a Coreia e a China. Esse alimento apresenta elevado teor de proteína vegetal e carboidratos, destacando-se pelo alto teor de fibras alimentares, vitaminas e minerais, além de possuir baixa quantidade de lipídios (KLOMKLAO et al., 2010; MUKAI; SATO, 2011). No Brasil, o feijão azuki ainda é pouco consumido, mas se adaptou bem às condições climáticas, sendo cultivado, na maioria das vezes, pelos descendentes dos imigrantes japoneses (GUARESCHI et al., 2013; GOHARA et al., 2016).

Os grãos do feijão azuki são pequenos e tem naturalmente sabor doce, sendo a cultivar de cor vermelha a mais apreciada pelos orientais. Vários estudos têm demonstrado que a casca vermelha do feijão azuki é rica em polifenóis, como procianidinas e quercetina, antioxidantes naturais que exercem ações benéficas no organismo, podendo prevenir o aparecimento de doenças cardiovasculares e alguns tipos de câncer (MARUYAMA et al., 2008; KLOMKLAO et al., 2010; MUKAI; SATO, 2011).

No Japão, o feijão azuki normalmente é usado na elaboração de vários tipos de bolos e doces (GUARESCHI et al., 2013; GOHARA et al., 2016). A partir do feijão azuki, são elaborados doces japoneses tradicionais como o "yokan", que é um doce em massa de feijão azuki endurecido com ágar (KLOMKLAO et al., 2010). Embora o doce de feijão seja pouco conhecido no Brasil, outros países, como o Peru, também têm receitas tradicionais de doce de feijão. $\mathrm{O}$ doce de feijão peruano pode ser definido como um doce em pasta de consistência cremosa, que leva, em sua composição, leite e açúcar.

O presente estudo teve como objetivo caracterizar quimicamente o feijão azuki vermelho cultivado no Brasil, além de avaliar o efeito do cozimento sobre o seu teor de compostos fenólicos e a sua atividade antioxidante. Este trabalho também desenvolveu formulações de doces de feijão e determinou a composição química desses doces.

\section{Material e métodos}

\subsection{Amostras}

Os feijões azuki (Vigna angularis) utilizados neste estudo foram cultivados na cidade de Rio Verde, Goiás, e adquiridos na cidade de Goiânia, Goiás. Os grãos crus foram triturados em moinho mecânico até se obter uma farinha com granulometria padronizada, através de passagem em peneira de 20 mesh. Em seguida realizaram-se as análises químicas.

\subsection{Análises físico-químicas}

As análises de composição química foram realizadas no Laboratório de Química e Bioquímica de Alimentos da Faculdade de Farmácia - Universidade Federal de Goiás
(UFG/GO). A análise de umidade foi determinada pela perda de peso do produto, submetido à secagem em estufa a $105^{\circ} \mathrm{C}$, durante quatro horas, até peso constante (HORWITZ, 2006). A análise de cinzas foi determinada pela perda de peso do produto, submetido à incineração a $550{ }^{\circ} \mathrm{C}$ em forno tipo mufla, modelo EDGCON 3P 3000 (EDG Equipamentos, São Carlos, São Paulo, Brasil) (HORWITZ, 2006). O nitrogênio total foi determinado pelo método de micro-Kjeldhal e a porcentagem de nitrogênio total foi convertida em proteína bruta, multiplicando os resultados pelo fator de conversão de 6,25 (HORWITZ, 2006). Os lipídios totais foram determinados segundo o método de Bligh e Dyer (1959). O teor de carboidratos foi determinado por diferença, sendo subtraída de 100 a soma dos teores de lipídios, proteínas, umidade e cinzas. O valor calórico total foi estimado conforme os valores de conversão de Atwater de $4 \mathrm{kcal} \mathrm{g}^{-1}$ de proteínas, $4 \mathrm{kcal} \mathrm{g}^{-1}$ de carboidratos e $9 \mathrm{kcal} \mathrm{g}^{-1}$ de lipídios (WILSON et al., 1982). Os açúcares redutores foram determinados utilizando-se o método do ácido 3,5-dinitrossalicílico (MILLER, 1959). Para determinar o teor de sacarose e açúcares totais, foi utilizado o método do ácido 3,5-dinitrossalicílico, com as modificações propostas por Silva et al. (2003). Os sólidos solúveis foram determinados através de refratômetro de bancada Shimadzu ${ }^{\circledR}$ e os resultados, expressos em ${ }^{\circ}$ Brix. Todas as análises foram realizadas em triplicata e os resultados foram apresentados como valores da média e desvio padrão.

A determinação da atividade antioxidante e dos compostos fenólicos das amostras do feijão azuki cru e cozido foi realizada nos extratos aquoso e alcoólico, utilizando-se a metodologia de extração descrita por Hassimoto et al. (2003). O feijão azuki foi cozido, sem maceração prévia, com água suficiente, em uma panela de pressão por 40 minutos. Os compostos fenólicos totais foram determinados de acordo com a Zieli ski e Kozłowska (2000), utilizando-se o reagente de Folin-Ciocalteu, sendo os resultados expressos em miligramas de equivalente de ácido gálico por 100 gramas de amostra (mg EAG $100 \mathrm{~g}^{-1}$ ). $A$ atividade antioxidante foi determinada utilizando-se 0 método do DPPH (1,1-difenil-2-picrilhidrazil), de acordo com Brand-Williams et al. (1995), com modificações de Borguini e Torres (2009). Esse método consiste na redução do radical estável DPPH através da ação dos antioxidantes presentes na amostra e esta redução foi medida por espectrofotometria a $517 \mathrm{~nm}$. Os resultados foram expressos como porcentagem de descoloração do radical DPPH. Todas as análises foram realizadas em triplicada e os resultados foram expressos como valor da média e desvio padrão.

\subsection{Elaboração dos doces de feijão azuki}

Para a elaboração do doce de feijão azuki em massa, o feijão azuki foi lavado em água corrente e seco. Pesou-se $1 \mathrm{~kg}$ de feijão e adicionaram-se 3,5 litros de 
água para o cozimento em panela aberta, por uma hora. O feijão cozido foi processado em liquidificador e, para a elaboração do doce de feijão, utilizaram-se $800 \mathrm{~g}$ de massa cozida, 1 kg de açúcar cristal e $16 \mathrm{~g}$ de ágar em pó, dissolvido em $200 \mathrm{~mL}$ de água. Procedeu-se à cocção do doce em panela de aço inoxidável, com agitação manual contínua, até concentração final de sólidos solúveis de $65^{\circ}$ Brix, medido em refratômetro. Após esta etapa, o doce foi vertido quente em uma forma de alumínio. No dia seguinte, o doce foi desenformado e cortado em fatias.

Para a elaboração do doce de feijão azuki em pasta, o feijão azuki foi lavado em água corrente e seco. Pesou-se $1 \mathrm{~kg}$ de feijão e adicionaram-se 4,0 litros de água para o cozimento em panela aberta, por uma hora. O feijão cozido foi separado da água de cozimento e batido em liquidificador, com a adição de dois litros de leite integral. Para a elaboração do doce de feijão, utilizou-se toda a massa de feijão, acrescentaram-se $790 \mathrm{~g}$ de leite condensado, $800 \mathrm{~g}$ de açúcar cristal e adicionou-se um sache de algodão contento 12 cravos e dois pedaços de canela. Procedeu-se à cocção do doce em panela de aço inoxidável, com agitação manual, até obter o ponto de doce em pasta (42 ${ }^{\circ}$ Brix). Após essa etapa, o doce foi envasado quente em embalagens de vidro (previamente esterilizadas) e estocado em geladeira.

\section{Resultados e discussão}

\subsection{Análises físico-químicas dos feijões azuki}

Os resultados das características químicas dos feijões azuki (Vigna angularis) estão apresentados na Tabela 1. Observou-se que o conteúdo de umidade (10,92\%) situou-se

Tabela 1. Composição química dos feijões azuki (Vigna angularis).

\begin{tabular}{cr}
\hline Componentes & \multicolumn{1}{c}{ Valores } \\
\hline Umidade $\left(\mathrm{g} 100 \mathrm{~g}^{-1}\right)$ & $10,92 \pm 0,08$ \\
Cinzas $\left(\mathrm{g} 100 \mathrm{~g}^{-1}\right)$ & $3,98 \pm 0,04$ \\
Proteínas $\left(\mathrm{g} 100 \mathrm{~g}^{-1}\right)$ & $17,87 \pm 0,03$ \\
Lipídios $\left(\mathrm{g} 100 \mathrm{~g}^{-1}\right)$ & $1,63 \pm 0,11$ \\
Carboidratos $\left(\mathrm{g} 100 \mathrm{~g}^{-1}\right)$ & $65,60 \pm 0,22$ \\
Valor calórico $\left(\mathrm{kcal} 100 \mathrm{~g}^{-1}\right)$ & $348,55 \pm 0,03$ \\
\hline
\end{tabular}

Os resultados são apresentados como médias \pm desvio padrão de três repetições, em base seca. dentro da faixa recomendada para o armazenamento de grãos, que é em torno de 13\% (IFERT et al., 2014). A umidade é um parâmetro importante no armazenamento de grãos, pois condições inadequadas podem diminuir a qualidade nutricional, bem como comprometer a segurança do produto (TOLEDO; CANNIATTI-BRAZACA, 2008). $\mathrm{O}$ armazenamento em ambiente de alta umidade causa o endurecimento dos grãos pós-colheita e, passando por longo tempo de cocção, os feijões azuki apresentam redução do valor nutricional (YOUSIF et al., 2003).

Os feijões azuki apresentaram elevado teor de carboidratos $(65,60 \%)$ e de proteínas $(17,87 \%)$, o que ressalta a importância do feijão como fonte de nutrientes na dieta humana. No trabalho de Gohara et al. (2016), as variedades de feijão azuki (Vigna angularis) cultivadas na cidade de Maringá, Paraná, apresentaram valores similares de composição química, com umidade de $13,07 \%$, carboidratos de $62,26 \%$ e proteínas de $20,36 \%$. Os feijões azuki deste estudo apresentaram baixo teor de lipídios (1,63\%) e, no estudo de Gohara et al. (2016), foram encontrados valores ainda menores de lipídios, ou seja, 0,45\%. Durak et al. (2013) também reportaram valores parecidos de proteínas (25,00\%), carboidratos (55,00\%) e lipídios totais $(0,45 \%)$ nos feijões azuki vermelhos.

Os teores de compostos fenólicos e a atividade antioxidante do feijão azuki cru e após sofrer o processo de cocção estão apresentados na Tabela 2. Observou-se que, na amostra de feijão cru, a quantidade de compostos fenólicos do extrato aquoso foi muito superior ao do extrato alcoólico. No trabalho de Gohara et al. (2016), foram encontrados valores de compostos fenólicos (81,87 mg EAC $100 \mathrm{~g}^{-1}$ ) similares a este estudo, no extrato dos feijões azuki em metanol. Essa diferença entre os extratos aquoso e alcoólico se deve principalmente à elevada concentração de compostos fenólicos solúveis em água, como as catequinas, no feijão azuki. Segundo Ramírez-Cárdenasi et al. (2008), o conteúdo de compostos fenólicos em feijões depende, em grande parte, de sua coloração e do tipo de feijão. O conteúdo de catequinas dos feijões pigmentados com casca é maior que nos feijões descascados, e os feijões vermelhos e pretos têm níveis significativamente maiores de catequinas que os feijões brancos.

Tabela 2. Teor de compostos fenólicos totais e atividade antioxidante dos feijões azuki cru e cozido.

\begin{tabular}{|c|c|c|c|c|}
\hline \multirow[t]{2}{*}{ Extratos } & \multicolumn{2}{|c|}{$\begin{array}{l}\text { Compostos fenólicos totais } \\
\left.\text { (mg EAG } 100 \mathrm{~g}^{-1}\right)\end{array}$} & \multicolumn{2}{|c|}{$\begin{array}{c}\text { Atividade antioxidante } \\
\text { (\% de descoloração do radical DPPH) }\end{array}$} \\
\hline & Feijão cru & Feijão cozido & Feijão cru & Feijão cozido \\
\hline Extrato aquoso & $1354,80 \pm 0,53$ & $18,50 \pm 0,63$ & $56,39 \pm 0,91$ & $21,05 \pm 0,15$ \\
\hline Extrato alcoólico & $76,82 \pm 0,50$ & $14,07 \pm 0,16$ & $7,74 \pm 0,16$ & $8,54 \pm 0,17$ \\
\hline Total & $1431,62 \pm 0,51$ & $32,57 \pm 0,44$ & $64,13 \pm 0,67$ & $29,59 \pm 0,11$ \\
\hline
\end{tabular}

Padrão de BHT $=96,92 \%$ de descoloração do radical DPPH. Os resultados são apresentados como médias \pm desvio padrão de três repetições. 
Neste trabalho, o conteúdo de compostos fenólicos totais do feijão azuki cru no extrato aquoso foi de $1.354,80 \mathrm{mg}$ EAG $100 \mathrm{~g}^{-1}$. No trabalho de Mukai e Sato (2011), as cascas vermelhas dos feijões azuki foram isoladas, moídas e secas, e apresentaram um elevado teor de compostos fenólicos totais, de 10.300 mg EAC $100 \mathrm{~g} \mathrm{~g}^{-1}$. As análises por HPLC mostraram uma composição de

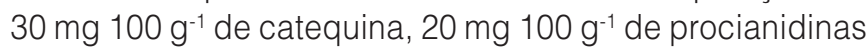

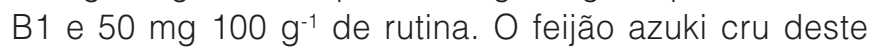
estudo mostrou alta atividade antioxidante $(64,13 \%$ de descoloração do radical DPPH), em comparação com polpas de frutas, como a sapota (CARVALHO et al., 2012) e o araçá (DAMIANI et al., 2011b), que mostraram, respectivamente, $27,85 \%$ e $12,75 \%$ de descoloração do radical DPPH.

Durante o processo de cocção, houve uma grande queda dos compostos fenólicos presentes no feijão azuki. No trabalho de Ramírez-Cárdenasi et al. (2008), também foi observado que o cozimento reduziu em até $81 \%$ os níveis de compostos fenólicos, em feijões comuns. Neste trabalho, observou-se também que o cozimento do feijão azuki resultou na perda de parte da atividade antioxidante. De acordo com Fernandes et al. (2010), o processamento térmico é, de longe, o fator que mais reduz o conteúdo tanto de fatores antinutricionais como de fatores nutricionais do feijão, sendo que um tempo de cozimento prolongado pode reduzir, em excesso, o teor de compostos fenólicos.

No trabalho de Xu e Chang (2009), os autores concluíram que a grande perda de compostos fenólicos e, consequentemente, de atividade antioxidante dos feijões estudados, ocorreu devido ao tratamento térmico. Também foi observado que a perda de atividade antioxidante no feijão cozido varia com o tipo de feijão, as condições de processamento e a composição de compostos fenólicos. No entanto, é interessante observar, neste estudo, que, no feijão azuki cozido, ainda há quase metade da porcentagem inicial de descoloração do radical DPPH
(29,59\%), indicando que o feijão azuki cozido apresentou boas propriedades antioxidantes.

\subsection{Análises físico-químicas dos doces de feijão azuki}

Os resultados da composição química dos doces de feijão azuki em massa e em pasta estão apresentados na Tabela 3. O teor de sólidos solúveis do doce em massa ficou de acordo com o valor estabelecido pela legislação brasileira, que é de $65,00^{\circ}$ Brix (BRASIL, 1978). O teor de açúcares totais $(59,07 \%)$ do doce de feijão em massa ficou parecido com o da geleia convencional de morango (62,38\%), do trabalho de Zambiazi et al. (2006), com a diferença de que todo o açúcar do doce de feijão foi representado por sacarose, não sendo detectada a presença de açúcares redutores em sua composição.

Os teores de umidade $(27,76 \%)$, lipídios $(0,33 \%)$ e carboidratos (67,09\%), e o valor calórico (287,41 $\mathrm{kcal}^{\left.100 \mathrm{~g}^{-1}\right)}$ do doce de feijão em massa podem ser comparados com os resultados obtidos para os doces de manga, formulados com diferentes composições de polpa e casca, que apresentaram os seguintes resultados: umidade: 21,11-30,38\%; lipídios: 0,12-0,28\%; carboidratos: 67,69\% a $76,15 \%$, e valor calórico: $278,37 \mathrm{kcal}$ a $313,00 \mathrm{kcal}$ (DAMIANI et al., 2011a).

No entanto, o teor de proteínas de $4,02 \%$ do doce de feijão em massa foi superior aos resultados dos doces de manga (DAMIANI et al., 2011a), que apresentaram 1,05\% a $1,57 \%$ de proteínas. O conteúdo proteico do doce de feijão pode ser comparado com o doce de leite (5,38\%), do estudo de Torres et al. (2000). Porém, o doce de feijão apresentou uma porcentagem mínima de lipídios de 0,33\%, enquanto que o doce de leite apresentou um teor de lipídios de 6,88\%. Devido ao baixo teor de lipídios, o valor calórico do doce de feijão em massa $\left(287,41 \mathrm{kcal}^{\left.100 \mathrm{~g}^{-1}\right)}\right.$


estudo de Torres et al. (2000).

Tabela 3. Valores médios da composição química dos doces de feijão azuki em massa e em pasta.

\begin{tabular}{|c|c|c|}
\hline \multirow{2}{*}{ Componentes } & \multicolumn{2}{|c|}{ Valores } \\
\hline & Doce em massa & Doce em pasta \\
\hline Umidade $\left(\mathrm{g} 100 \mathrm{~g}^{-1}\right)$ & $27,76 \pm 0,06$ & $43,60 \pm 0,27$ \\
\hline Cinzas (g $\left.100 \mathrm{~g}^{-1}\right)$ & $0,80 \pm 0,08$ & $1,00 \pm 0,08$ \\
\hline Proteínas (g $\left.100 \mathrm{~g}^{-1}\right)$ & $4,02 \pm 0,07$ & $6,48 \pm 0,03$ \\
\hline Lipídios (g $100 \mathrm{~g}^{-1}$ ) & $0,33 \pm 0,01$ & $2,73 \pm 0,02$ \\
\hline Carboidratos (g $\left.100 \mathrm{~g}^{-1}\right)$ & $67,09 \pm 0,14$ & $46,20 \pm 0,37$ \\
\hline Sólidos solúveis ( $\left.{ }^{\circ} \mathrm{Brix}\right)$ & $65,00 \pm 0,01$ & $42,00 \pm 0,01$ \\
\hline Açúcares redutores $\left(\mathrm{g} 100 \mathrm{~g}^{-1}\right)$ & 0,00 & $3,68 \pm 0,01$ \\
\hline Sacarose $\left(\mathrm{g} 100 \mathrm{~g}^{-1}\right)$ & $59,07 \pm 0,03$ & $28,32 \pm 0,03$ \\
\hline Açúcares Totais (g $100 \mathrm{~g}^{-1}$ ) & $59,07 \pm 0,03$ & $32,00 \pm 0,02$ \\
\hline Valor calórico (kcal $100 \mathrm{~g}^{-1}$ ) & $287,41 \pm 0,04$ & $235,39 \pm 0,03$ \\
\hline
\end{tabular}

Os resultados são apresentados como médias \pm desvio padrão de três repetições, em base úmida. 

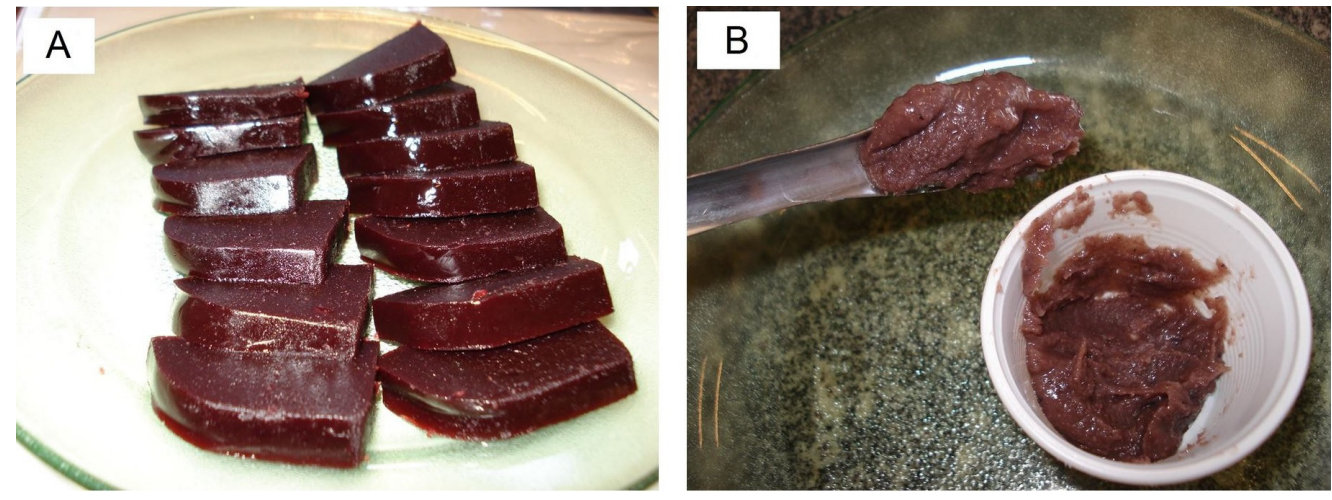

Figura 1. Aspecto dos doces de feijão azuki: (A) doce em massa; e (B) doce em pasta.

Já o doce de feijão azuki em pasta apresentou 32,00\% de açúcares totais, sendo a maior parte constituída por sacarose $(28,32 \%)$ e uma pequena quantidade, por açúcares redutores glicose e lactose (3,68\%). Observou-se que o conteúdo de umidade do doce em pasta (43,60\%) situou-se acima do valor máximo recomendado pela legislação, que é de 30\% (BRASIL, 1978). Devido ao alto teor de umidade, o doce de feijão em pasta teve de ser armazenado sob refrigeração, para garantir a sua correta preservação, sem risco de crescimento de micro-organismos.

O teor de proteínas $(6,48 \%)$ do doce de feijão em pasta ficou parecido com o resultado obtido para o doce de leite, no estudo de Torres et al. (2000), com teor de proteínas de 5,38\%. Porém, os valores de lipídios (6,88\%) e carboidratos $(58,14 \%)$, no doce de leite do estudo de Torres et al. (2000), foram maiores que os valores de lipídios $(2,73 \%)$ e carboidratos $(46,20 \%)$ do doce de feijão azuki em pasta. No trabalho de Sousa et al. (2002), também foram encontrados valores mais elevados para os carboidratos (média de 62,62\%) e lipídios (média de 10,76\%), nas amostras estudadas de doce de leite de búfala. Devido ao menor teor de lipídios e carboidratos, o valor calórico do doce de feijão azuki em pasta $\left(235,39\right.$ kcal $\left.100 \mathrm{~g}^{-1}\right)$ foi menor que o do doce de leite de búfala (média de $\left.382,52 \mathrm{kcal} 100 \mathrm{~g}^{-1}\right)$.

Com relação à aparência, a cor vermelha escura e o aspecto brilhante dos doces de feijão azuki em massa e em pasta deixaram os produtos com um visual bastante atrativo (Figura 1).

\section{Conclusões}

O feijão azuki apresentou elevado teor de carboidratos de 65,60 g $100 \mathrm{~g}^{-1}$ e de proteínas de 17,87 g $100 \mathrm{~g}^{-1}$. O feijão azuki cozido, apesar de ter perdido grande parte dos seus compostos fenólicos durante o cozimento, ainda manteve aproximadamente metade da atividade antioxidante em relação ao feijão cru, podendo ser considerado um alimento cozido com boas propriedades antioxidantes. O feijão azuki mostrou ter um bom potencial tecnológico para sua utilização no processamento dos doces de feijão. Os doces formulados com feijão azuki apresentaram vantagens em relação aos doces tradicionais, como o doce de leite, por terem, em sua composição, um maior teor de proteínas e um menor teor de lipídios, o que contribuiu para esses doces apresentarem um menor valor calórico. Embora os doces de feijão azuki sejam pouco conhecidos pelos brasileiros, a aparência dos doces tem potencial para atrair os consumidores.

\section{Referências}

BLIGH, E. G.; DYER, W. J. A rapid method of total lipid extraction and purification. Canadian Journal of Biochemistry and Physiology, v. 37, n. 8, p. 911-917, 1959. PMid:13671378. http:// dx.doi.org/10.1139/059-099.

BORGUINI, R. G.; TORRES, E. A. F. S. Tomatoes and tomato products as dietary sources of antioxidants. Food Reviews International, v. 25, n. 4, p. 313-325, 2009. http://dx.doi. org/10.1080/87559120903155859.

BRAND-WILLIAMS, W.; CUVELIER, M. E.; BERSET, C. Use of a free radical method to evaluate antioxidant activity. Canadian Journal of Biochemistry and Physiology, v. 28, n. 1, p. 25-30, 1995.

BRASIL. Ministério da Saúde. Resolução Normativa n 9, de 1978 - CNNPA. Define termos sobre doce em pasta. Diário Oficial [da] República Federativa do Brasil, Brasília, DF, 11 dez. 1978. Disponível em: <http://www.anvisa.gov.br/legis/ resol/09_78_doces.htm>. Acesso em: 21 jul. 2016.

CARVALHO, V. S.; DAMIANI, C.; ASQUIERI, E. R.; ORSI, D. C.; NISHI, A. C. F. Development and antioxidant capacity of sapota pulp jelly (Quararibea cordata Vischer). Ciência e Agrotecnologia, v. 36, n. 3, p. 341-347, 2012. http://dx.doi.org/10.1590/S141370542012000300010 .

DAMIANI, C.; ALMEIDA, A. C. S.; FERREIRA, J.; ASQUIERI, E. R.; VILAS BOAS, E. V.; SILVA, F. A. Doces de corte formulados com casca de manga. Pesquisa Agropecuária Tropical, v. 41, n. 3, p. 360-369, 2011a. http://dx.doi.org/10.5216/pat.v41i3.9815. 
Caracterização química, atividade antioxidante e formulação de doces com feijão azuki (Vigna angularis) Orsi, D. C. et al.

DAMIANI, C.; VILAS BOAS, E. V.; ASQUIERI, E. R.; LAGE, M. E.; OLIVEIRA, R. A.; SILVA, F. A.; PINTO, D. M.; RODRIGUES, L. J.; SILVA, E. P.; PAULA, N. R. F. Characterization of fruits from the savanna: Araça (Psidium guinnensis Sw.) and Marolo (Annona crassiflora Mart.). Ciência e Tecnologia de Alimentos, v. 31, n. 3, p. 723-729, 2011b. http://dx.doi.org/10.1590/S010120612011000300026

DURAK, A.; BARANIAK, B.; JAKUBCZYK, A.; ŚWIECA, M. Biologically active peptides obtained by enzymatic hydrolysis of Adzuki bean seeds. Food Chemistry, v. 141, n. 3, p. 2177-2183, 2013. PMid:23870945. http://dx.doi.org/10.1016/j. foodchem.2013.05.012.

FERNANDES, A. C.; NISHIDA, W.; PROENÇA, R. P. C. Influence of soaking on the nutritional quality of common beans (Phaseolus vulgaris L.) cooked with or without the soaking water: a review. International Journal of Food Science \& Technology, v. 45, n. 11, p. 2209-2218, 2010. http://dx.doi.org/10.1111/j.13652621.2010.02395.x.

GOHARA, A. K.; SOUZA, A. H. P.; GOMES, S. T. M.; SOUZA, N. E.; VISENTAINER, J. V.; MATSUSHITA, M. Nutritional and bioactive compounds of adzuki bean cultivar using chemometric approach. Ciência e Agrotecnologia, v. 40, n. 1, p. 104-113, 2016. http:// dx.doi.org/10.1590/S1413-70542016000100010

GUARESCHI, R. F.; PERIN, A.; ROCHA, A. C.; ANDRADE, D. N. Adubação com cama de frango e esterco bovino na produtividade de feijão azuki (Vigna angularis). Revista Agrarian, v. 6, n. 19, p. 29-35, 2013.

HASSIMOTO, N. M. A.; GENOVESE, M. I.; SANTOS, R. J.; LAJOLO, F. M. Determinação do conteúdo de fenólicos totais em frutas. Revista Brasileira de Ciências Farmacêuticas, v. 39, n. 3, p. 167-169, 2003

HORWITZ, W. (Ed.). Official methods of analysis of the Association of Official Analytical Chemists. 18th ed. Gaithersburg: AOAC; 2006.

IFERT, E. C.; SILVA, J. G.; FONSECA, J. R.; VIEIRA, E. H. N. Secagem, beneficiamento e armazenamento de grãos. In: GONZAGA, A. C. O. Feijão: o produtor pergunta, a Embrapa responde. 2. ed. Brasília: Embrapa, 2014

KLOMKLAO, S.; BENJAKUL, S.; KISHIMURA, H.; OSAKO, K.; TANAKA, M. A heat-stable trypsin inhibitor in azuki bean (Vigna angularis): effect of extraction media, purification and biochemical characteristics. International Journal of Food Science \& Technology, v. 45, n. 1, p. 163-169, 2010. http:// dx.doi.org/10.1111/j.1365-2621.2009.02117.x

MARUYAMA, C.; ARAKI, R.; KAWAMURA, M.; KONDO, N.; KIGAWA, M.; KAWAI, Y.; TAKANAMI, Y.; MIYASHITA, K.; SHIMOMITSU, T. Azuki bean juice lowers serum triglyceride concentrations in healthy young women. Journal of Clinical Biochemistry and Nutrition, v. 43, n. 1, p. 19-25, 2008. PMid:18648655. http:// dx.doi.org/10.3164/jcbn.2008039.

MILLER, G. L. Use of dinitrosalicylic acid reagent for determination of reducing sugar. Analytical Chemistry, v. 31, n. 4, p. 426-428, 1959. http://dx.doi.org/10.1021/ac60147a030.
MUKAI, Y.; SATO, S. Polyphenol-containing azuki bean (Vigna angularis) seed coats attenuate vascular oxidative stress and inflammation in spontaneously hypertensive rats. The Journal of Nutritional Biochemistry, v. 22, n. 1, p. 16-21, 2011. PMid:20185287. http://dx.doi.org/10.1016/j.jnutbio.2009.11.004.

RAMÍREZ-CÁRDENASI, L.; LEONEL, A. J.; COSTA, N. M. B. Efeito do processamento doméstico sobre o teor de nutrientes e de fatores antinutricionais de diferentes cultivares de feijão comum. Ciência e Tecnologia de Alimentos, v. 28, n. 1, p. 200-213, 2008. http://dx.doi.org/10.1590/S0101-20612008000100029.

SILVA, R. N.; MONTEIRO, V. N.; ALCANFOR, J. D. X.; ASSIS, E. M.; ASQUIERI, E. R. Comparação de métodos para a determinação de açúcares redutores e totais em mel. Ciência e Tecnologia de Alimentos, v. 23, n. 3, p. 337-341, 2003. http://dx.doi.org/10.1590/ S0101-20612003000300007.

SOUSA, C. L.; NEVES, E. C. A.; CARNEIRO, C. A. A.; FARIAS, J. B.; PEIXOTO, M. R. S. Avaliação microbiológica e físicoquímica de doce de leite e requeijão produzidos com leite de búfala na Ilha do Marajó- PA. Boletim do Centro de Pesquisa de Processamento de Alimentos, v. 20, n. 2, p. 192-202, 2002.

TOLEDO, T. C. F.; CANNIATTI-BRAZACA, S. G. Avaliação química e nutricional do feijão carioca (Phaseolus vulgaris L.) cozido por diferentes métodos. Ciência e Tecnologia de Alimentos, v. 28 , n. 2, p. 355-360, 2008. http://dx.doi.org/10.1590/S010120612008000200013.

TORRES, E. A. F. S.; CAMPOS, N. C.; DUARTE, M.; GARBELOTTI, M. L.; PHILIPPI, S. T.; RODRIGUES, R. S. M. Composição centesimal e valor calórico de alimentos de origem animal. Ciência e Tecnologia de Alimentos, v. 20, n. 2, p. 145-150, 2000. http://dx.doi.org/10.1590/S0101-20612000000200003.

WILSON, E. D.; SANTOS, A. C.; VIEIRA, E. C. Energia. In: DUTRAOLIVEIRA, J. E.; SANTOS, A. C.; WILSON, E. D. Nutrição básica. São Paulo: Sarvier, 1982. p. 80-94

XU, B. J.; CHANG, S. K. C. Total phenolic, phenolic acid, anthocyanin, flavan-3-ol, and flavonol profiles and antioxidant properties of pinto and black beans (Phaseolus vulgaris L.) as affected by thermal processing. Journal of Agricultural and Food Chemistry, v. 57, n. 11, p. 4754-4764, 2009. PMid:19492791. http://dx.doi.org/10.1021/jf900695s.

YOUSIF, A. M.; BATEY, I. L.; LARROQUE, O. R.; CURTIN, B.; BEKES, F.; DEETH, H. C. Effect of storage of adzuki bean (Vigna angularis) on starch and protein properties. LebensmittelWissenschaft + Technologie, v. 36, n. 6, p. 601-607, 2003. http://dx.doi.org/10.1016/S0023-6438(03)00078-1.

ZAMBIAZI, R. C.; CHIM, J. F.; BRUSCATTO, M. Avaliação das características e estabilidade de geleias light de morango. Alimentos e Nutrição, v. 17, n. 2, p. 165-170, 2006.

ZIELIŃSKI, H.; KOZŁOWSKA, H. Antioxidant activity and total phenolic in selected cereal grains and their different morphological fractions. Journal of Agricultural and Food Chemistry, v. 48, n. 6, p. 2008-2016, 2000. PMid:10888490. http://dx.doi. org/10.1021/jf990619o. 